\title{
Coupling between the Grain for Green Program and a household level-based agricultural eco-economic system in Ansai, Shaanxi Province of China
}

\author{
LI Yue ${ }^{1}$, WANG Jijun ${ }^{1,2^{*}}$, HAN Xiaojia ${ }^{2}$, GUO Mancai ${ }^{1}$, CHENG Simin $^{2}$, QIAO Mei ${ }^{1}$, ZHAO \\ Xiaocui $^{1}$ \\ ${ }^{1}$ Institute of Soil and Water Conservation, Northwest A\&F University, Yangling 712100, China; \\ ${ }^{2}$ Institute of Soil and Water Conservation, Chinese Academy of Sciences and Ministry of Water Resources, Yangling 712100, \\ China
}

\begin{abstract}
The implementation of the Grain for Green Program (GGP) has changed the development track of the agricultural eco-economic system in China. In response to the results of a lag study that investigated the coupling between the GGP and the agricultural eco-economic system in a loess hilly region, we used a structural equation model to analyze the survey data from 494 households in Ansai, a district of Yan'an City in Shaanxi Province of China in 2015. The model clarified the direction and intensity of the coupling between the GGP and the agricultural eco-economic system. The coupling benefits were derived through linkages between the program and various chains in the agricultural eco-economic system. The GGP, the agroecosystem of Ansai and their potential coupling effects were in a state of general coordination. The agroecosystem directly affected the coupling effect, with the standardized path coefficient of 0.87 , indicating that the agroecosystem in Ansai at this stage provided basic material support for the coupling between the GGP and the agricultural eco-economic system. The direct path coefficient of agroeconomic system impacted on the coupling effect was -0.76 , indicating that partial contradictions occurred between the agroeconomic system and the coupling effect. Therefore, although the current agroecosystem in Ansai should be provided sufficient agroecological resources for the benign coupling between the program and the agricultural eco-economic system, agricultural development failed to effectively transform agroecological resources into agricultural economic advantages in this region, which resulted in a relative lag in the development of the agricultural economic system. Thus, the coupling between the GGP and the agricultural eco-economic system was poor. To improve the coupling and the sustainable development of the agricultural eco-economic system in cropland retirement areas, the industrial structure needs to be diversified, the agricultural resources (including agroecological resources, agricultural economic resources and agricultural social resources) need to be rationally allocated, and the chain structure of the agricultural eco-economic system needs to be continuously improved.
\end{abstract}

Keywords: Grain for Green Program; agroecosystem; agroeconomic system; agrosocial system; coupling effect; household; structural equation model

Citation: LI Yue, WANG Jijun, HAN Xiaojia, GUO Mancai, CHENG Simin, QIAO Mei, ZHAO Xiaocui. 2020. Coupling between the Grain for Green Program and a household level-based agricultural eco-economic system in Ansai, Shaanxi Province of China. Journal of Arid Land, 12(2): 199-214. https://doi.org/10.1007/s40333-020-0060-3

\footnotetext{
${ }^{*}$ Corresponding author: WANG Jijun (E-mail: jjwang@ms.iswc.ac.cn)

Received 2019-01-11; revised 2019-11-28; accepted 2019-12-10

(C) Xinjiang Institute of Ecology and Geography, Chinese Academy of Sciences, Science Press and Springer-Verlag GmbH Germany, part of Springer Nature 2020
} 


\section{Introduction}

Over the last two decades, the Grain for Green Program (GGP) has been the largest ecological restoration project in China, with a total budget of $4.30 \times 10^{11} \mathrm{CNY}$ (Uchida et al., 2005; Bennett, 2008; Liu et al., 2008) and an implementation area of $29.08 \times 10^{7} \mathrm{hm}^{2}$. The GGP is an ecosystem restoration and reconstruction process that can lead to changes in land use. Through the program, forest coverage in areas of cropland retirement has increased by an average of more than $3 \%$ (State Forestry Administration of the People's Republic of China, 2016). As a consequence of the wide implementation of the program, the GGP has become an important area of research (Xu et al., 2006), with the focus on scientific evaluation of its benefits. The land cover rate in cropland retirement areas has improved substantially under the implementation of the GGP (Liu and Wu, 2010), which is associated with important decreases in soil erosion and sandstorms (Yao et al., 2010; Liu et al., 2013; Li et al., 2018). In areas with the program, economic development and social progress have also benefited ( $\mathrm{Li}$ et al., 2016a). Although many researchers agree that implementation of the program will bring tremendous ecological and social benefits to cropland retirement areas, technical changes are also thought to be needed to improve outcomes of the program (Xu et al., 2006).

Opinions differ widely on the ecological and economic effects of the GGP. Jia et al. (2014) reported that the GGP provided great ecological benefits by contributing to climate regulation. Wang et al. (2014) investigated changes in the sustainable development of the agricultural system in Yanchi County of Northwest China by using a synthetic emergy evaluation before and after the implementation of the GGP in 2001. The outputs of the regional agricultural system increased from 1991 to 2008 but then gradually declined. They concluded that increased investment in nonrenewable resources reduced the effects of program implementation and hindered the introduction of policies to save energy and reduce emissions. Li et al. (2016b) used farmer data collected from Ansai (a district of Yan'an City) in Shaanxi Province of China in 2010 and developed a structural equation model to analyze the program results. They found that although the implementation of the GGP improved the family life of farmers and promoted local agricultural transformation, it also caused the loss of local labor and led to cultivated land being left idle.

The coupling of the ecological and economic systems is traditional in practice. Ren et al. (1995) simulated the coupling effect in an oasis agricultural system and found that the overall social benefits increased 3.7-fold and the economic benefits of livestock increased 15.7-fold under normal operations and sustainable ecosystem use. Wang et al. (2010) simulated the coupling of the agricultural ecosystems in small watersheds of Ansai for 70 a and identified four stages in the coupling process after cropland retirement: (1) a stage of primitive agricultural production in which the economic system depends on the ecological resources; (2) a stage in which agricultural production exploits the ecological resources and the ability of the system to supply resources decreasing unceasingly; (3) a stage of coordinated development of the agricultural and economic systems; and (4) a stage in which the speed of agricultural development is reduced and reconstruction of the agricultural ecosystem is promoted. Although from different perspectives, these studies attempted to clarify the ecological response mode and the degree and direction of the economic effects derived from the GGP at both spatial and temporal scales. The results are of great practical value in the formulation of regional sustainable development plans and the optimal allocation of factors. However, the coupling between the GGP and the agricultural system has yet to be fully explored.

Ansai is a typical loess hilly and gully region and is therefore ecologically fragile. Thus, the region was selected as an experimental area for the GGP, with cropland retirement beginning as early as 1999. The region has experienced substantial agricultural eco-economic and social benefits since the implementation of the GGP. Li et al. (2018) clarified the coupling between the GGP and the agricultural system in Ansai; furthermore, the evolution of the coupling process between the two has been studied as a whole. However, the coupling relationship can only reflect the coupled trend between the GGP and the agricultural eco-economic system; it does not reflect the coupling effect within the systems, which is important, because several levels of coupling 
effects exist under the same coupling relationship. Additionally, the specific paths of the coupling between the GGP and the agricultural eco-economic system remain unclear. Therefore, it is particularly important to clarify the process underlying the internal interaction, association and function between the GGP and the agricultural eco-economic system. In this research, the goal was to help optimize the GGP, adjust the structure of the agricultural eco-economic system, and promote the coupling between the two.

Structural equation models have been utilized to examine the latent and explicit variables involved in the coupling paths (McCune and Grace, 2002). They can be used to analyze the latent variables involved in a system and can also be used to study the relationships between latent variables by observing their covariance. For example, Li et al. (2012) used the structural equation model to study the coupling relationships between the commercial, ecological and agricultural systems in Ansai, in addition to clarifying the intrinsic relationships among those main coupling elements. The studies of $\mathrm{Li}$ et al. $(2012,2018)$ demonstrated that the structural equation models can be used to analyze the coupling paths connecting the GGP and the agricultural system. Additionally, samples need to be collected within the same time period to use the structural equation model. In this study, the actual production situations in Ansai were combined with the research perspective of farmer choice. Because households are the direct implementers and beneficiaries of the GGP, the program has had large and far-reaching effects on the production and lives of local rural communities (Grosjean and Kontoleon, 2009). Thus, the selection of household as the basic unit to conduct a sample survey with questionnaires can more accurately reflect the effects of the GGP on the agroecosystem, agroeconomic system and agrosocial system in cropland retirement areas. The aim of this study was to determine the coupling relationships, paths and intensity of interaction among various core elements involved in the coupling between the GGP and the agricultural eco-economic system in Ansai, in addition to providing information that can be used to improve the coupling and sustainable development of the agricultural eco-economic systems in cropland retirement areas.

\section{Materials and methods}

\subsection{Study area}

The study area is located in Ansai $\left(36^{\circ} 30^{\prime} 45^{\prime \prime}-37^{\circ} 19^{\prime} 31^{\prime \prime} \mathrm{N}, 108^{\circ} 51^{\prime} 44^{\prime \prime}-109^{\circ} 26^{\prime} 18^{\prime \prime} \mathrm{E}\right.$; Fig. 1), a district in the northern part of Yan'an City, Shaanxi Province, China. The average elevation is $1371.9 \mathrm{~m}$ a.s.1. and the total area of Ansai is $2.95 \times 10^{3} \mathrm{~km}^{2}$, which accounts for $8.04 \%$ of the total area of Yan'an City. The study area is characterized by a mid-temperate continental semi-arid monsoon climate with four distinct seasons. The average annual frost-free period is $160 \mathrm{~d}$, the annual average temperature is $9.1{ }^{\circ} \mathrm{C}$ and the average annual precipitation is $506.6 \mathrm{~mm}$. Ansai is a typical hilly and gully region on the Loess Plateau. The terrain of Ansai is fragmented and the ecological environment is poor. After the implementation of the GGP in 1999, the area affected by soil erosion has been greatly reduced. The soil erosion control rate reached $46.00 \%$, and the soil erosion modulus decreased from $14.00 \times 10^{3} \mathrm{t} /\left(\mathrm{km}^{2} \cdot \mathrm{a}\right)$ in 1998 to $5.40 \times 10^{3} \mathrm{t} /\left(\mathrm{km}^{2} \cdot \mathrm{a}\right)$ in $2004(\mathrm{Li}$ et al., 2018). The land cover rate increased from $18.00 \%$ in 1998 to $34.68 \%$ in 2016 . The population of Ansai was $19.7 \times 10^{4}$ in 2016 , which included an agricultural population of $15.1 \times 10^{4}$. Under the national plan (i.e., the GGP), a total of $81.75 \times 10^{3} \mathrm{hm}^{2}$ of cropland retirement $\left(43.33 \times 10^{3} \mathrm{hm}^{2}\right.$ of returning farmland lands $\left(0.07 \mathrm{hm}^{2}\right.$ per farmer; Li et al., 2018), $36.62 \times 10^{3} \mathrm{hm}^{2}$ of barren hills and wasteland and $1.80 \times 10^{3} \mathrm{hm}^{2}$ of hillside) was designated for afforestation. At present, the GGP has involved 204 administrative villages in Ansai and the accumulated funds (including a food discount) have reached $10.62 \times 10^{8} \mathrm{CNY}$. A total of $31.00 \times 10^{3}$ households have returned cropland to forestland; and the per capita income of farmers has been subsidized with $7.80 \times 10^{3} \mathrm{CNY}$, benefiting more than $98.00 \%$ of farmers in Ansai.

\subsection{Data source}

The data involved in the analysis and model calculation were obtained from a farmer survey conducted in Ansai from July to August, 2016. The farmer survey adopted a random sampling 


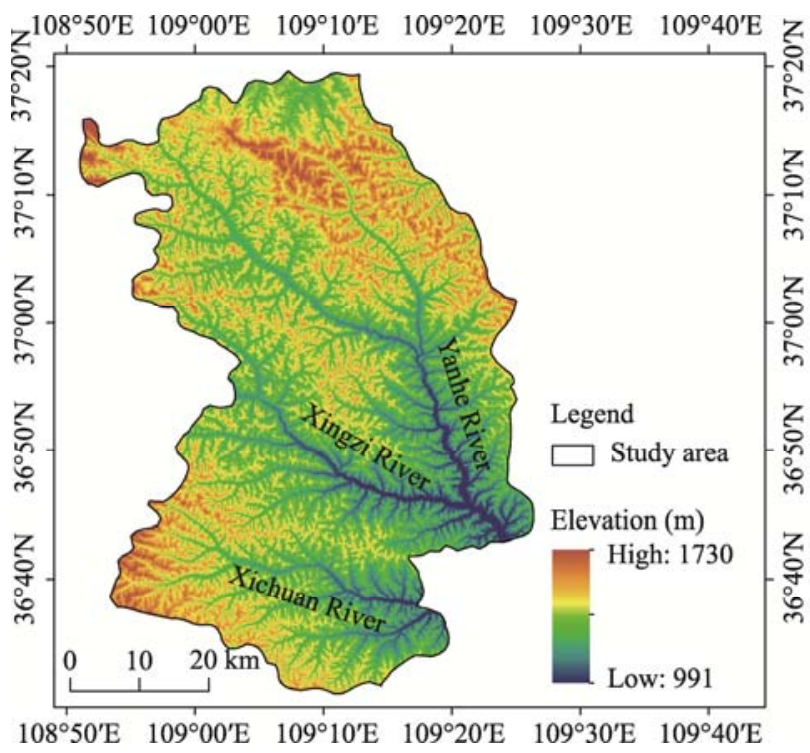

Fig. 1 Overview of the study area

method and involved 52 administrative villages in eight townships across three parts (southern, middle and northern) of Ansai. The survey focused on the farmer population and labor force, the eco-economic forest structure after the implementation of the GGP, land use, per capita basic farmland, orchard plot proportion, agricultural production and management, the development of industries and sideline industries, farmer income and expenditure, changes in agricultural labor management, farmer degree of satisfaction with life, and forest and grass quality of cropland retirement areas. The survey lasted for one and a half months and the average household was interviewed 1-2 $\mathrm{h}$. The interviewees were members of the family who were primarily engaged in agricultural production (mostly male). A total of 612 households were surveyed, which resulted in an effective sample size of 494 households, with 163, 176 and 155 households in the southern, middle and northern parts of Ansai, respectively. The survey parameters satisfied the requirements for structural equation modeling (Aderson and Gerbring, 1988).

\subsection{Research methods}

The structural equation model consists of two models: a structural model and a measurement model. The structural model defines the linear relationship between independent variables and potential dependent variables, and the measurement model defines the linear relationship between latent variables and observed variables (Bertalanffy, 1987; Rong, 2009). The equations for the model were as follows:

$$
\begin{gathered}
\eta=\beta \eta+\gamma \xi+\zeta, \\
Y=\lambda_{y} \eta+\varepsilon, \\
X=\lambda_{x} \eta+\delta,
\end{gathered}
$$

Equation 1 is the structural equation, where $\eta$ is an endogenous latent variable; $\beta$ is the interaction coefficient between endogenous latent variables; $\gamma$ is the effective coefficient of the exogenous latent variable on the endogenous latent variable, also known as the path coefficient of the exogenous latent variable on the endogenous latent variable; $\xi$ is a standardized exogenous variable; and $\zeta$ is the residual vector of $\eta$. Equation 2 is a measurement equation for endogenous latent variables (i.e., dependent variables), where $Y$ is the vector composed of endogenous observation variables; $\lambda_{y}$ is the factor load matrix of the endogenous observation variable on the endogenous latent variable, which indicates the relationships between the endogenous latent variable and the endogenous observed variable; and $\varepsilon$ is the residual matrix of the measurement model. Equation 3 is a measurement equation for an exogenous latent variable (independent variable), where $X$ represents a vector composed of exogenous observations; $\lambda_{x}$ is the factor load 
matrix of the exogenous observed variable on the exogenous latent variable, which indicates the relationships between the exogenous latent variable and the exogenous observed variable; and $\delta$ is the residual matrix of the measurement model.

The structural equation model has advantages over most other linear-in-parameter statistical methods (Tomarken et al., 2005; Werner and Schermelleh-Eagel, 2009), including the evaluation of alternative models, prediction of the responses of dependent variables to changes in independent variables and partitioning of direct and indirect effects (Li et al., 2016b). The structural equation model provides a specific parameterization of model structure by making a strong and explicit connection between empirical data and theoretical ideas (Grace et al., 2010). The analysis process can be divided into four steps: model construction, model calculation, model correction and model interpretation (Steiger, 1990; Asah, 2008; Sutton et al., 2010). The model is a combination of confirmatory factor analysis and path analysis (Wright, 1934; Gough and Grace, 1999) and can be used to analyze complex, immediate interactions among elements within a system (Bollen, 1989; Maruyama, 1998; Duncan et al., 2006).

\section{Model construction}

\subsection{Construction of the structural equation model}

When there is an open composite system between the GGP and the agricultural eco-economic system, a coupling path is formed using the interactions between different factors, such as population, resources, environment, policy, science and technology, which comprehensively reflect the coupling between the GGP and the agricultural eco-economic system.

For the purpose of this study, we identified five latent variables based on the development trajectory of the agricultural eco-economic system in Ansai (Li et al., 2012, 2018). Of which, two were endogenous variables, namely, the GGP $(\xi 1)$ and the coupling effect of the implementation of the GGP (coupling effect; $\eta 4$ ); and three were exogenous latent variables, namely, the agricultural ecosystem (agroecosystem; $\eta 1$ ), the agricultural economic system (agroeconomic system; $\eta 2$ ) and the agricultural social system (agrosocial system; $\eta 3$ ). With the implementation of the GGP, the structure of the ecological forest and the economic forest reflects the relationship between ecological protection and economic development, whereas the quality of the ecological forest determines the degree of restoration and reconstruction of an ecosystem. Therefore, two observed variables, "eco-economic forest structure $(x 1)$ " and "forest and grass quality of cropland retirement areas $(x 2) "$, were selected to characterize the program. The regional ecosystem included the status of the ecological environment and the utilization of the ecological resources. Therefore, the "forest and grass area rate $(y 1)$ " and the representative "per capita basic cropland $(y 2)$ ", which can represent the ecological environment of the region, were selected to represent the agroecosystem. The agroeconomic system in a region is primarily represented by the industrial situation and economic benefits (Lei, 2009). Therefore, the "agricultural labor ratio (y3)" and the "agricultural commodity rate $(y 4) "$ were selected to characterize the agroeconomic system. While improving the ecological environment and economic functions, the program also directly affected the values for labor and population in a cropland retirement area. Therefore, the "renewal of values $(y 5)$ " was selected to represent the agrosocial system. The agrosocial system was also represented by the variable "life satisfaction ( $y 6$ )", which was measured from a behavioral point of view. Human behavior is based on predictable outcomes of behavior, and people are willing to perform only if they improve their lives. As the export of this composite system, three observation variables were selected to characterize the coupling effect. These variables were "relevance of the agricultural industry resource chain (y7)" (reflecting the status of an agricultural system), "land use structure of agriculture, forestry and animal husbandry $(y 8) "$ (reflecting the development of the coupling between an agroecosystem and an agroeconomic system) and "per capita net income (y9)" (reflecting the development level of an agricultural system). The categories, specific definitions and methods used to obtain the observed variables under each latent variable are explained in Table 1. 
Table 1 Interpretation of system variables in the synergistic mechanism linking the Grain for Green Program (GGP) and the agricultural eco-economic system

\begin{tabular}{lll}
\hline $\begin{array}{l}\text { Latent variable } \\
\text { category }\end{array}$ & Observable variable & \multicolumn{1}{c}{ Definition and calculation method for the observable variable } \\
\hline $\begin{array}{l}\text { GGP } \\
(\xi 1)\end{array}$ & $\begin{array}{l}\text { Eco-economic forest } \\
\text { structure } x 1 \text { (total score } \\
\text { for each item: } 1-6)\end{array}$ & $\begin{array}{l}\text { The structure of an eco-economic forest reflects the implementation process of the GGP } \\
\text { and the allocation and proportion of ecological forests and economic forests after the } \\
\text { implementation. The aim is to determine the suitability of the composition of ecological } \\
\text { forests and economic forests for the regional natural conditions and whether their ratio }\end{array}$
\end{tabular}
is within the threshold set by the state.

Scale: moderate ratio between economic forests and ecological forests (1, No; 2 , Generally; 3, Yes).

Forest and grass quality Forest and grass quality of a cropland retirement area reflects the level of ecological of cropland retirement areas $x 2$ (total score for each item: $0-3)$ restoration of the converted forest and grassland. If the area of cropland retirement reflects the level of ecological restoration on the basis of scale, the quality reflects the intensity of the restoration, and the community structure and tree species diversity are the cores of characterization.

Scale: structure of the community is reasonable $(0 \mathrm{No} ; 1 \mathrm{Yes})+$ there is a diverse range of species $(0$, No; 1 , Yes $)+$ there is a balance between economic and ecological benefits (0, No; 1 , Yes).

Agroecosystem Forest and grass area ( $\eta 1)$ rate $y 1(\%)$

Per capita basic cropland $y 2$

Agroeconomic system $(\eta 2)$

Agricultural labor ratio y3 (\%)

Agricultural commodity rate $y 4(\%)$

Agrosocial system $(\eta 3)$

Renewal of values $y 5$ (total score for each item: 0-2)
Life satisfaction $y 6$ (total score for each item: 4-12)
Coupling effect (n4)
Relevance of the agricultural industry resource chain $y 7$ (total score for each item: 19)
Land use structure for agriculture, forestry and animal husbandry y8 (\%) Per capita net income y9
Forest and grass area rate is the sum of woodland and grassland areas divided by the area of available land.

Scale: percentage of directly calculated results.

Per capita basic cropland refers to the basic cropland area divided by the total population.

Scale: percentage of directly calculated results.

Agricultural labor ratio refers to the agricultural labor divided by the sum of agricultural labor and non-agricultural labor.

Scale: percentage of directly calculated results.

Agricultural commodity rate refers to the commodity volume of agricultural products divided by the agricultural output.

Scale: percentage of directly calculated results.

The renewal of values reflects the changes in people's production and management concept, the regulation of their own behavior, and the degree of changes in self-awareness caused by the return of cropland to forestland with project implementation.

Scale: degree of understanding of important national policies and guidelines (1, Do not know; 2, Not comprehensive; 3 , Comprehensive understanding)+changes in the concept of democracy and rule of law (1, No; 2, Slightly; 3, Exist)+technology training activities (1, No; 2, Slightly; 3, Exist)+changes in market concept before and after the return of cropland to forestland (1, Weakened; 2, No; 3, Enhanced)+proportion of basic living consumption and cultural education consumption after the return of cropland (1, Life consumption proportion is larger; 2, Basically the same; 3, Cultural education consumption is larger).

Life satisfaction reflects people's cognition, perception and self-satisfaction and is an evaluation of the core elements of social life after the GGP.

Scale: changes in social order and social atmosphere after the return of cropland (1, Exist; 2, No; 3, Slightly)+satisfaction with current social security situation (1, Dissatisfied; 2, Basic satisfaction; 3, Satisfied)+degree of improvement in social order and social improvement after the return of cropland (1, No; 2, Not obvious; 3, Significantly improved)+frequency of participation in social activities and village collective activities increased after the return of cropland to forestland (1, No; 2, Small increase; 3, Significantly increased).

Relevance of the agricultural industry resource chain is the support and correlation between related agricultural industries, which primarily reflects the relationship between leading industries and related industries and follow-up industries.

Scale: 1 , extensive cultivation and reclamation; 2 , extensive cultivation; 3 , single grain; 4, agricultural fruit, agriculture and animal husbandry; 5, agricultural fruit development, forestry and animal husbandry; 6 , mainly industry; 7 , formation of related industries; 8 , organic and unified relationship among industries; 9, a virtuous combination of ecological, economic and social systems.

Land use structure for agriculture, forestry and animal husbandry reflects the allocation and proportion of various land resources in the process of land use.

It is difficult to determine in the actual analysis process, and therefore, the process is expressed as the ratio of cultivated land to forestland and grassland area.

Per capita net income is: total revenue-production cost/population. Scale: actual value of the calculation. 
The following ten hypotheses were made on the basis of the above analysis about the regional GGP and the agricultural system coupling mechanism: H1, the GGP has a direct effect on the agroecosystem; H2, the GGP has a direct effect on the agroeconomic system; H3, the GGP has a direct effect on the agrosocial system; H4, the agroecosystem is coupled to the agroeconomic system; H5, the agroecosystem is correlated with the agrosocial system; H6, the agroeconomic system has a direct effect on the agrosocial system; H7, the agroecosystem has a direct effect on the coupling effect; H8, the agroeconomic system has a direct effect on the coupling effect; H9, the agrosocial system has a direct effect on the coupling effect; and H10, a relationship exists between the GGP and the coupling effect.

The conceptual model is shown in Figure 2, where e1-e16 are the residual variables, which indicate the part of the endogenous variable that cannot be interpreted by the exogenous variable.

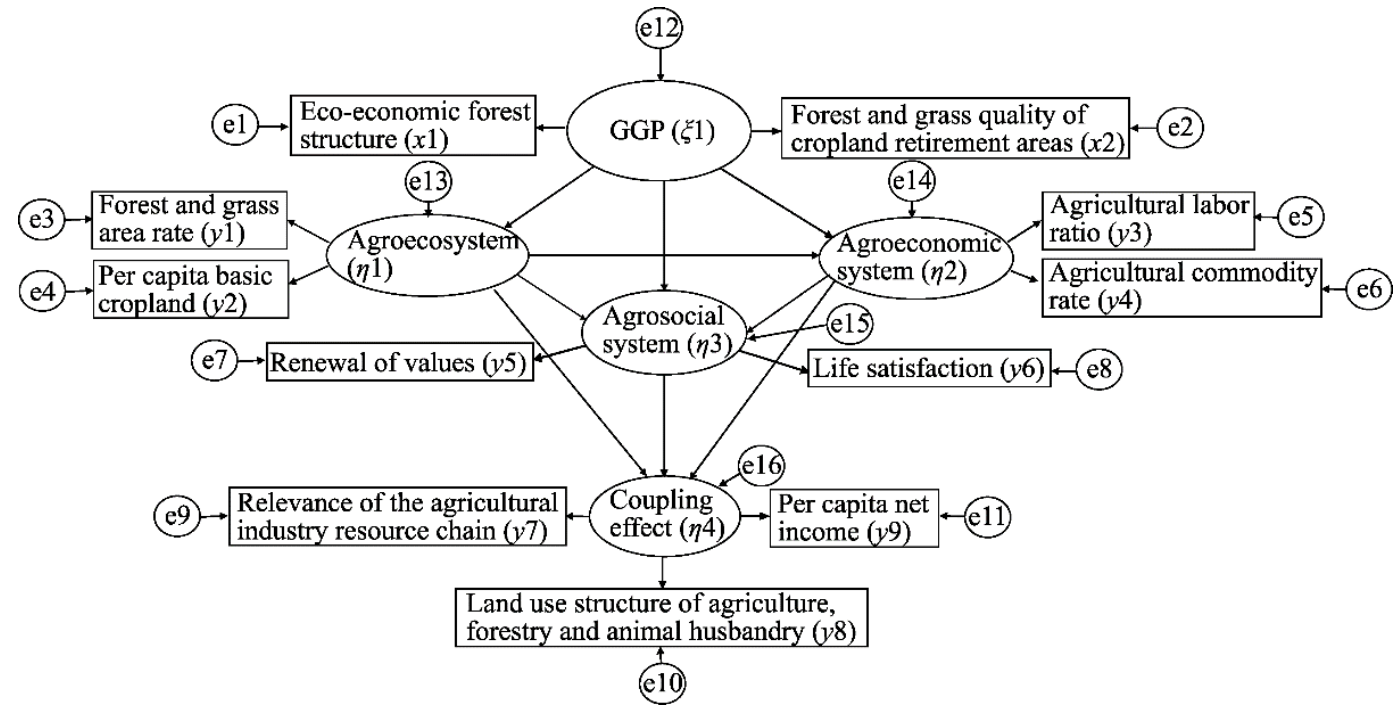

Fig. 2 Conceptual model of the coupling relationships between the Grain for Green Program (GGP) and the agricultural eco-economic system in Ansai. Agroecosystem represents the agricultural ecosystem; agroeconomic system represents the agricultural economic system; and agrosocial system represents the agricultural social system. Latent variables are shown in ellipses and observed variables are shown in boxes; e1-e16 are the residual variables, which indicate the part of the endogenous variable that cannot be interpreted by the exogenous variable; $\mathrm{e} \rightarrow$ is the measurement error of a variable, and the details of which are shown in Table 1. All path coefficients are shown as standardized coefficients to compare the direct effects among variables.

\subsection{Model implementation}

\subsubsection{Data processing and reliability analysis}

To eliminate the influence of various observed variables due to magnitude and dimensional differences, we used the SPSS 23.0 (IBM, Amund, NY, USA) statistical package to standardize the surveyed data from 494 households in Ansai. The variable reliability was analyzed using Cronbach's $\alpha$ method, which can evaluate the effect of each excluding indicator on the overall reliability of the scale and suggest the scores of indicators that should be reversed (Asah, 2008). Cronbach's $\alpha$ values for the latent variables were all higher than 0.70 , which indicated that the data had a good consistency, and therefore, the model was reliable.

\subsubsection{Model fitting}

The structural equation model was used to analyze the latent variables, observable variables and their relationships in coupling paths connecting the GGP and the agricultural eco-economic system. The calculation was performed using Amos21.0 software (IBM, Amund, NY, USA) and the surveyed data from the households were used to evaluate the model and the model parameters. The maximum likelihood method was used to estimate the model parameters, because the surveyed data were obtained through simple sampling, which satisfied the precondition of the method (Byrne, 2001). The fitted model obtained after parameter estimation was completed. 
Then, the degree of the model fit was evaluated by testing the rationality of the parameters (for example, the relevant parameters should be between -1 and +1 ), their significance, the size of the coefficient of determination and the fitting index (Hou et al., 2004). The tests can give a quantitative basis for the rationality of the model and provide direction for further research and improvement of the model (Wang et al., 2017). Additionally, in this study, the degree of the model fit was evaluated by examining the significance of the fitted model path coefficient divided by the load factor and the fit index. In the evaluation process, if the ratio of path coefficient to load factor ( $P$ value) was greater than the 5\% significance level, then the path was not significant. Thus, the model should be modified by expanding the model (releasing some paths or adding new paths) or introducing model restrictions (deleting or restricting some paths) (Byrne, 1998) to form a new model with a better fit.

\section{Results}

The model fitted reasonably well on the basis of the test results for the structural equation model (Tables 2 and 3). The dataset of Ansai supported this model and had a good fit (Table 2). Thus, our model exhibited sufficient validity. Eight of the ten hypotheses (except for hypotheses H4 and H10) in the initial conceptual model were accepted.

Table 2 Fitting indices for the structural equation model

\begin{tabular}{crccrrrrrr}
\hline & $X^{2} / d f$ & RMSEA & GFI & TLI & CFI & IFI & PNFI & PCFI \\
\hline Reference standard & $<3.00$ & $<0.10$ & $>0.90$ & $>0.90$ & $>0.90$ & $>0.90$ & $>0.50$ & $>0.50$ \\
Evaluation result & 2.99 & 0.07 & 0.91 & 0.90 & 0.91 & 0.90 & 0.51 & 0.51 \\
\hline
\end{tabular}

Note: $d f$, degree of freedom; RMSEA, root mean square error of approximation; GFI, goodness of fit index; TLI, Tucker-lewis index; CFI, comparative fit index; IFI, incremental fit index; PNFI, parsimony normed-fit index; PCFI, parsimony comparative-fit index.

Table 3 Overall standard influence coefficients

\begin{tabular}{cccccc}
\hline & $\xi 1$ & $\eta 1$ & $\eta 2$ & $\eta 3$ & 0.00 \\
\hline 1 & 0.12 & 0.00 & 0.00 & 0.000 & 0.00 \\
$\eta 2$ & 0.24 & 0.85 & 0.00 & 0.000 & 0.00 \\
$\eta 3$ & -0.03 & 0.04 & 0.56 & 0.000 & 0.00 \\
$\eta 4$ & -0.07 & 0.22 & -0.74 & 0.038 & 0.00 \\
$x 1$ & 0.68 & 0.00 & 0.00 & 0.000 & 0.00 \\
$x 2$ & 0.55 & 0.00 & 0.00 & 0.000 & 0.00 \\
$y 1$ & -0.05 & -0.40 & 0.00 & 0.000 & 0.00 \\
$y 2$ & 0.10 & 0.79 & 0.00 & 0.000 & 0.00 \\
$y 3$ & 0.13 & 0.48 & 0.57 & 0.000 & 0.00 \\
$y 4$ & -0.03 & -0.10 & -0.12 & 0.000 & 0.00 \\
$y 5$ & -0.01 & 0.01 & 0.12 & 0.214 & 1.31 \\
$y 6$ & -0.02 & 0.03 & 0.38 & 0.685 & -0.02 \\
$y 7$ & 0.00 & -0.01 & 0.02 & -0.001 & 1.70 \\
$y 8$ & -0.13 & 0.38 & -1.26 & 0.064 & -0.04 \\
$y 9$ & 0.00 & 0.01 & -0.002 & \\
\hline
\end{tabular}

Note: Estimates between the column and row variables denote that when the column variable goes up by 1.00, the row variable goes up by the estimated value. The total effect contains the sum of all paths, including direct and indirect effects (Hung et al., 2007).

\subsection{Results of the model correction}

The model corrections allowed a model to be performed better (Fig. 3; Tables 2-4). The corrected model for the study area fitted well with the dataset, and the model fitting indices were within a reasonable range, which verified the rationality and effectiveness of the initial conceptual model (Fig. 2). The significance levels of the complete paths and compound paths are shown in Tables 4 and 5 , respectively. 


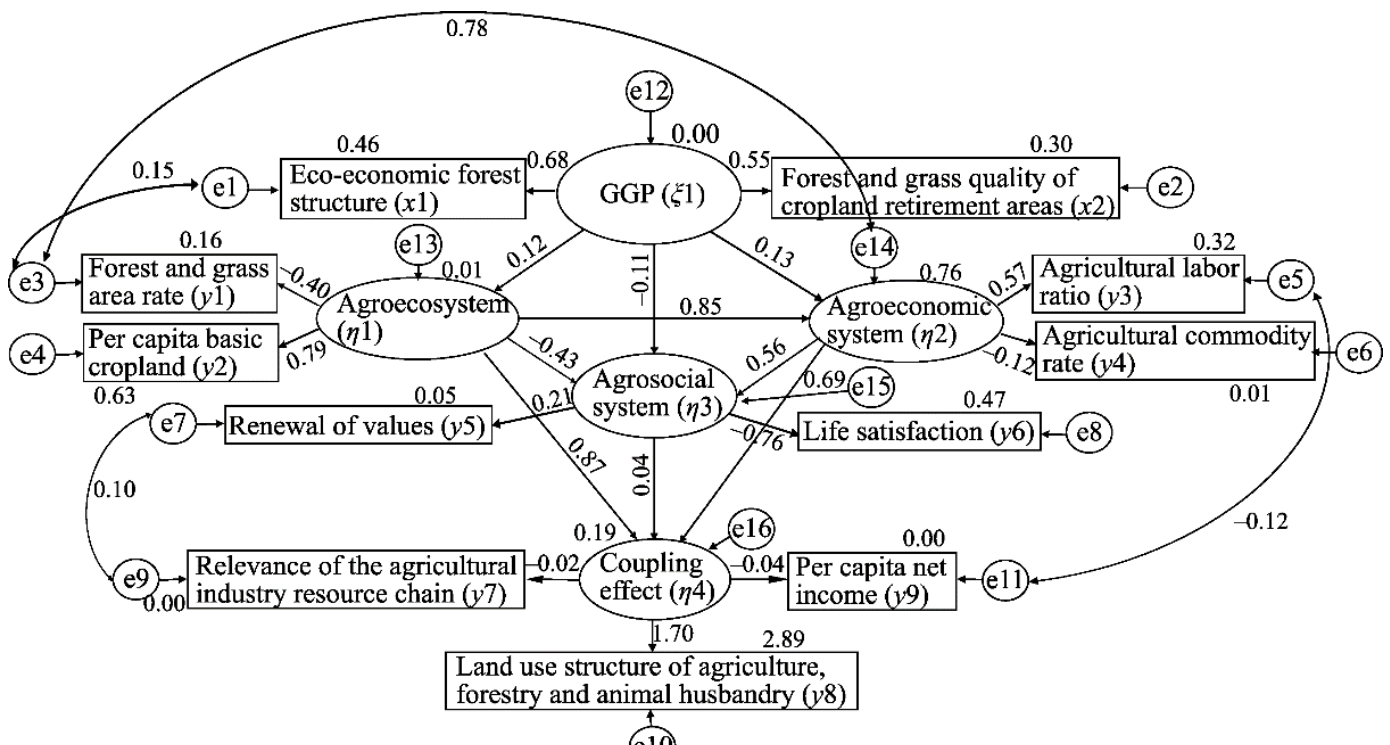

(e10)

Fig. 3 Coupling relationships between the GGP and the agricultural eco-economic system function model in Ansai. Latent variables are shown in ellipses and observed variables are shown in boxes; e1-e16 are the residual variables, which indicate the part of the endogenous variable that cannot be interpreted by the exogenous variable. Estimates are standardized regression weights of $\mathrm{B} \rightarrow \mathrm{A}$ and correlations between $\mathrm{B} \leftrightarrow \mathrm{A}$ ( $\mathrm{A}$ and $\mathrm{B}$ mean any parameters in Fig. 3). The path coefficient greater than 0.00 means that the direct and indirect impacts of the exogenous variable on the endogenous variable are positive; however, the path coefficient lower than 0.00 means that the direct and indirect impacts of the exogenous variable on the endogenous variable are negative.

Table 4 Standardized model coefficients of the corrected model

\begin{tabular}{cccc}
\hline & Paths & & $P$ \\
\hline Agroecosystem $(\eta 1)$ & $\leftarrow$ & GGP $(\xi 1)$ & 0.01 \\
Agroeconomic system $(\eta 2)$ & $\leftarrow$ & GGP $(\xi 1)$ & 0.04 \\
Agroeconomic system $(\eta 2)$ & $\leftarrow$ & Agroecosystem $(\eta 1)$ & $* * *$ \\
Agrosocial system $(\eta 3)$ & $\leftarrow$ & Agroecosystem $(\eta 1)$ & 0.03 \\
Agrosocial system $(\eta 3)$ & $\leftarrow$ & Agroeconomic system $(\eta 2)$ & 0.03 \\
Agrosocial system $(\eta 3)$ & $\leftarrow$ & GGP $(\xi 1)$ & 0.04 \\
Coupling effect $(\eta 4)$ & $\leftarrow$ & Agrosocial system $(\eta 3)$ & 0.03 \\
Coupling effect $(\eta 4)$ & $\leftarrow$ & Agroeconomic system $(\eta 2)$ & 0.01 \\
Coupling effect $(\eta 4)$ & $\leftarrow$ & Agroecosystem $(\eta 1)$ & $* * *$ \\
\hline
\end{tabular}

Note: $P$ values represent the levels of significance for regression weights and correlations. *** means $P$ value $\leq 0.001$.

Table 5 Standardized model coefficients for the compound paths of the corrected model

\begin{tabular}{|c|c|c|c|c|c|c|c|}
\hline \multicolumn{7}{|c|}{ Compound paths } & \multirow{2}{*}{$\begin{array}{c}P \\
0.01\end{array}$} \\
\hline & & $\begin{array}{c}\text { Coupling effect } \\
(\eta 4)\end{array}$ & $\leftarrow$ & $\begin{array}{c}\text { Agroecosystem } \\
(\eta 1)\end{array}$ & $\leftarrow$ & GGP $(\xi 1)$ & \\
\hline & & $\begin{array}{l}\text { Coupling effect } \\
\qquad(\eta 4)\end{array}$ & $\leftarrow$ & $\begin{array}{l}\text { Agroeconomic system } \\
\qquad(\eta 2)\end{array}$ & $\leftarrow$ & GGP $(\xi 1)$ & 0.05 \\
\hline & & $\begin{array}{l}\text { Couplingeffect } \\
\qquad(\eta 4)\end{array}$ & $\leftarrow$ & $\begin{array}{l}\text { Agrosocial system } \\
\qquad(\eta 3)\end{array}$ & $\leftarrow$ & $\operatorname{GGP}(\xi 1)$ & 0.08 \\
\hline $\begin{array}{c}\text { Coupling effect } \\
(\eta 4)\end{array}$ & $\leftarrow$ & $\begin{array}{c}\text { Agrosocial system } \\
(\eta 3)\end{array}$ & $\leftarrow$ & $\begin{array}{l}\text { Agroecosystem } \\
(\eta 1)\end{array}$ & $\leftarrow$ & GGP $(\xi 1)$ & 0.08 \\
\hline $\begin{array}{c}\text { Coupling effect } \\
(\eta 4)\end{array}$ & $\leftarrow$ & $\begin{array}{c}\text { Agrosocial system } \\
(\eta 3)\end{array}$ & $\leftarrow$ & $\begin{array}{l}\text { Agroeconomic system } \\
(\eta 2)\end{array}$ & $\leftarrow$ & GGP $(\xi 1)$ & 0.11 \\
\hline
\end{tabular}

To further understand the results, it is necessary to examine the path coefficients, which indicate the strength of the direct and indirect impacts of the exogenous variable on the 
endogenous variable (Brahim et al., 2011). All factor loadings had $P$ values smaller than 0.05 ; therefore, all of the path coefficients were significant (Table 4). If there were multiple paths from an exogenous variable to an endogenous variable, then the total impact contained the sum of all paths (Hung et al., 2007). As shown in Table 5, not all of the compound path coefficients were significant.

\subsection{Analysis of path development based on the coupling between the GGP and the agricultural eco-economic system}

The coupling effect is based on the agricultural eco-economic system. The GGP affects the coupling effect through the direction and strength of the agricultural eco-economic system. In the process of the coupling development for the GGP and agricultural eco-economic system in Ansai, four elements worked together: the GGP, the agroecosystem, the agroeconomic system and the agrosocial system. The agroecosystem, agroeconomic system and agrosocial system directly affected the coupling effect, with standardized path coefficients of $0.87,-0.76$, and 0.04 (Fig. 3), respectively, which were consistent with the actual results obtained from the household survey. This result was an indication that the focus of the GGP was on ecology and that the implementation of the GGP greatly improved the agroecosystem in the region. The coupling within the composite system was also promoted. However, the development of the agroeconomic system did not play an appropriate role in promoting the coupling of the composite system. Furthermore, the degree of the agrosocial system development had little effect on the coupling development of the composite system.

After the implementation of the GGP in Ansai, the forest and grass vegetation in the area was restored, and the forest and grass resources increased significantly. The terraced fields in the returned cropland accelerated the construction of agriculture with efficient facilities, which improved the development of fruit trees and economic forests on terraced fields and gentle slopes. This series of measures enabled the agroecosystem in Ansai to provide sufficient material and energy for a coordinated development process. The results indicated that the agroecosystem was the key element that was improved by the implementation of the GGP. Because the direct path coefficient of the agroecosystem impacted on the coupling effect was 0.87 , the optimization of the agroecosystem improved the overall system function when the GGP was implemented. The optimization was due to the development of fruit trees and economic forests on terraced fields and gentle slopes that promoted the agricultural economy within the system.

However, the development of fruit trees and economic forests only made a small contribution to the structural adjustment of the agricultural economy, and the economic development of the region depended primarily on economic income from outside the system. According to the survey, the non-agricultural income was more than twice the agricultural income in Ansai (Table 6). Thus, although the GGP substantially increased the availability of the agricultural resources, those resources were not used effectively. Furthermore, the production structure failed to adjust in time, which led to a lag in the development of the agroeconomic system across the region. Therefore, the production structure could not support the comprehensive functional improvement of the system.

Table 6 Total income derived from the agricultural and non-agricultural incomes based on surveyed data in Ansai

\begin{tabular}{cccc}
\hline & Total income & Agricultural income & Non-agricultural income \\
\hline Income of interviewed 494 households $\left(\times 10^{4} \mathrm{CNY}\right)$ & 2961.39 & 897.21 & 2064.18 \\
Proportion $(\%)$ & 100.00 & 30.30 & 69.70 \\
\hline
\end{tabular}

From the perspective of the agrosocial system, at the present stage, a large number of labor force transfer has changed the original way of production, life and ideology due to the implementation of the GGP. However, the development rate of the agrosocial system under the implementation of the GGP was relatively slow, and therefore, the contribution of the agrosocial system to the development of the coupling between the GGP and the agricultural eco-economic system was also low. The program indirectly affected the coupling effect through its indirect 
effect on the agricultural eco-economic system, although the coefficient for the standardized path was -0.07 (Table 3), which was inconsistent with hypothesis H10 (a relationship exists between the GGP and the coupling effect). This result can be explained primarily because the GGP affected the system by changing the function of various chain structures in the agricultural eco-economic system. In this process, a positive effect was observed between the agroecosystem and the coupling effect, and a negative effect was observed between the agroeconomic system and the coupling effect (Fig. 2), ultimately leading to a negative effect of the GGP on the coupling effect.

\subsection{Roles of the agroecosystem, agroeconomic system and agrosocial system in the coupling between the GGP and the agricultural eco-economic system}

The agroecosystem, agroeconomic system and agrosocial system in Ansai were effectively allocated according to the needs of the national ecological construction. The agricultural eco-economic system was the basis for the development of the coupling between the GGP and the agricultural eco-economic system. Therefore, the position and function of the agricultural eco-economic system were investigated in the development of the coupling between the GGP and the agricultural eco-economic system.

The development of positive coupling was an indication that the GGP improved the agricultural eco-economic system. Therefore, hypothesis H4 (the agroecosystem is coupled to the agroeconomic system) was not established. The agroecosystem had a single effect on the agroeconomic system, with the path coefficient of 0.85 , indicating that optimization of the agroecosystem during the implementation of the GGP increased the agroecological resources, which played a supporting role in the development of the agroeconomic system in the region. However, the development of the agroeconomic system did not lead to an effective utilization of the increased the agroecological resources created by the optimization of the agricultural eco-economic system, because the system lacked the structural integration of industrial chain, agricultural labor, agricultural income proportion, etc. Furthermore, the development of the agroeconomic system depended primarily on outside factors. These factors led to a reduced demand for agroecological resources in the region, and therefore, the development of the agricultural economy did not play a positive role in promoting the optimization of the agroecosystem.

As shown in Figure 3, the agroecosystem in Ansai negatively affected the agrosocial system, with the path coefficient of -0.43 , which indicated that incentive incompatibilities existed between the agroecosystem and the agrosocial system. The primary explanation for this result may be that the eco-economic development was at the 'demand for life development' stage (Wang et al., 2017), indicating that the life satisfaction of farmers was mainly focused on the improvement of economic income. However, because the agricultural resources were not fully utilized, the economic income of farmers was more dependent on outside resources than on the resources generated through the optimization of the agroecosystem, which ultimately led to a contradiction between the agroecosystem and the agrosocial system.

The path coefficient of the agroeconomic system impacted on the agrosocial system was 0.56 , which suggested that the GGP resulted in a coupling between the agroeconomic system and the agrosocial system, although the coupling was not obvious.

\subsection{Roles of observed variables and the difference in their contribution to the coupling between the GGP and the agricultural eco-economic system}

The direct action path of each latent variable was a main factor affecting the system coupling in the model. The correlations between different observed variables also reflected the relationships among the corresponding latent variables. The correlation coefficient between the forest to grass area rate (e3) and the eco-economic forest structure standardization (e1) was 0.15 (Fig. 3). This indicated that there was a positive correlation between the forest and grass area rate and the eco-economic forest structure, which also revealed that the optimization of the structure of eco-economic forest had a certain effect on the improvement of the forest to grass area ratio and 
ecological restoration. The positive correlation proved that implementing the GGP promoted the optimization and improvement of the agroecosystem in the region. A negative correlation (correlation coefficient of -0.12) was observed between the agricultural labor ratio (e5) and per capita net income (e11), suggesting that the development of a regional agroeconomic system depended primarily on the economic development of non-agricultural industries. The per capita net income of farmers derived from non-agricultural income was consistent with the results of the household survey (Tables 6 and 7), which demonstrated that the development of the agroeconomic system was relatively slow.

Table 7 Sizes and proportions of the household agricultural and non-agricultural labor force based on the surveyed data in Ansai

\begin{tabular}{cccc}
\hline & Total labor & Agricultural labor & \multicolumn{2}{c}{ Non-agricultural labor } \\
force & force & \\
\hline Labor force of interviewed 494 households (people) & 1637 & 771 & 866 \\
Proportion $(\%)$ & 100.00 & 47.10 & 52.90 \\
\hline
\end{tabular}

Furthermore, the standardized coefficient values between observed variables and associated latent variables illustrated the relative importance of each observed indicator's contribution to the associated latent variable (Hung et al., 2007). As shown in Figure 3, with regard to the latent variable of the GGP, the contribution made by the eco-economic forest structure (0.68) was greater than that made by the forest and grass quality of cropland retirement areasquality of the returned cropland and grassland $(0.55)$, which indicated that the structure of the eco-economic forest changed substantially after the GGP was implemented. The forest and grass quality of cropland retirement areas determined the survival rate for afforestation and the suitability of tree species and local soil. Different plant species could be selected on the basis of local conditions, for example, trees and forages. This principle in the GGP also had a considerable effect on the forest and grass quality of cropland retirement areas. According to the household survey, approximately $79.8 \%$ of households considered rationality of community structure and $78.9 \%$ of households considered rationality of tree species diversity. Thus, most farmers were satisfied with the forest and grass quality of cropland retirement areas (Table 8). As our model results shown in Figure 3, a negative correlation was detected between the relevance of the agricultural industry resource chain and the coupling effect, which indicated that the increase in resources due to the implementation of the GGP was not utilized by regional-related industries. Therefore, these resources did not have a positive effect on the coupling effect.

Table 8 Forest and grass quality of cropland retirement areas based on the household survey

\begin{tabular}{cccc}
\hline & $\begin{array}{c}\text { Rationality of } \\
\text { community structure }\end{array}$ & $\begin{array}{c}\text { Rationality of tree } \\
\text { species diversity }\end{array}$ & $\begin{array}{c}\text { Moderate proportion of } \\
\text { eco-economic forest }\end{array}$ \\
\hline $\begin{array}{c}\text { Effective interviewed 494 } \\
\text { households (households) }\end{array}$ & 394 & 389 & 310 \\
Proportion (\%) & 79.80 & 78.90 & 62.10 \\
\hline
\end{tabular}

\section{Discussion}

As presented in Figure 3, the total impact of the GGP on the coupling effect was -0.07 and the total impact of the GGP on the agrosocial system was -0.03 , suggesting that the coupling effect between the GGP and the agrosocial system was negative, which did not completely coincide with the theory that the GGP and the agricultural eco-economic system can fully positively develop the coupling. Therefore, we conducted a depth analysis to further clarify the reasons.

\subsection{Verification of the rationality of each component involved in the coupling between the GGP and the agricultural eco-economic system}

A structural equation model was established in this study, and then, the paths of various elements involved in the coupling between the GGP and the agricultural eco-economic system in Ansai were clarified. The structural equation model identified the GGP, the coupling effect, the 
agroecosystem, the agroeconomic system and the agrosocial system as the core elements that affected the coupling effect within the program. These elements supported one another and formed a new functional body, demonstrating that the choice of elements and the formation of the coupling relationships were reasonable.

In general, the path relationships formed by the five elements mentioned above were generally consistent with the theory that the GGP and the agricultural eco-economic system can fully positively develop the coupling, but there were some differences between the actual situation and the theoretical results. The effect of the agroecosystem on the coupling effect was positive in Ansai, which indicated that the agroecosystem provided a potential resource for the benign coupling between the GGP and the agricultural system. By contrast, the direct contradictions were observed between the agroeconomic system and the coupling effect, indicating that all the indirect effects on the coupling produced by the agroeconomic system were weakened, which led to a divergence in the development of the coupling between the GGP and the agricultural eco-economic system.

The lag in the development of regional agroeconomic system can explain the inconsistency. One reason for the lag was that after the implementation of the GGP, the traditional grazing mode used by farmers was transformed into a captive farming mode, which led to the forest and grassland resources being wasted or lying idle and not being used to support the animal husbandry development. The second reason was that only a small amount of gentle sloping land and terraced fields was available for production after the conversion of large areas to cropland retirement areas. Furthermore, much of the agricultural labor force was transformed into the non-agricultural labor force, which led to insufficient regional kinetic energy (Uchida et al., 2009) and could not effectively transform the resource and ecological environment advantages into economic advantages. These results demonstrated again that the economic factor dominates the decisions about future sustainable development of the returning cropland to forestland (Kalaitzandonakes and Monson, 1994). Thus, the coupling between the agroeconomic system and the coupling effect was poor, and ultimately, the coupling effect was not optimized. The agricultural eco-economic system failed to provide feedback on the implementation of the GGP that was predicted by theory. The inadequate development of the agroeconomic system leading to poor coupling with the internal agricultural eco-economic system was the primary reason for this failure, indicating that insufficient driving forces were generated to propel the implementation of the GGP.

\subsection{Consistencies and deviations between the GGP and the agricultural eco-economic system}

Although the agricultural eco-economic system was the core for the development of the coupling, this core role was partially inconsistent with the actual internal coordination identified by this study. The direct relationship between the agroecosystem and the agroeconomic system and the indirect role of the agrosocial system were positive, but the direct effect between the agroecosystem and the agrosocial system appeared to be negative. Some of the action paths were inconsistent with the assumptions in the initial conceptual model, namely, the agroeconomic system only acted on the agrosocial system in one direction and did not have an effect on the agroecosystem. This result showed that under the implementation of the GGP, little interaction occurred between the agricultural eco-economic systems. The inconsistency between the agroeconomic system and agroecological resources indicated that they lagged behind the agroecosystem development, further implying that they could not produce a feedback effect.

Therefore, the coupling effect did not achieve the best theoretical results among the agroecosystem, agroeconomic system and agrosocial system. Li et al. (2012) concluded that the ecological environment, agricultural resources and industrial situation were coupled in Ansai. However, because the improvement in the ecological environment did not play a fundamental or supportive role in the system coupling, the coupling relationship between the agricultural resources and the industrial situation was poor. This situation led to a poor coupling within the agricultural eco-economic systems. According to the above analyses, the agroecological resources 
generated by ecological improvement were not effectively utilized. At present, the agricultural eco-economic system in Ansai is not yet coupled well with the program. However, after five years of development, the forest and grass resources in Ansai will increase substantially, the development in high-efficiency facilities is rapid and the results for agroecosystem optimization in the region are highly positive. Compared with the previous study of Li et al. (2012), the current agroecosystem in Ansai had the conditions that should provide sufficient agroecological resources for the benign coupling between the GGP and the agricultural eco-economic system. According to the current increase in resources and combined with the requirement of the "Two Mountains Theory" (a theory that aims to make a tradeoff between development and protection), Wang et al. (2017) suggested that changing the form of resource utilization would be the breakthrough for the current system to optimize and upgrade. On one hand, the direct utilization rate of resources should be improved. On the other hand, the potential economic value of ecological functions should be highlighted, and a carbon sink industry should be developed to continuously increase the sustainable development vitality of cropland retirement areas (Smith and Scherr, 2003).

\subsection{Suggestions for improving the coupling between the GGP and the agricultural eco-economic system}

The characteristics of the coupling between the GGP and the agricultural eco-economic system and the above-mentioned path coefficients demonstrated that it is possible for coupling to develop. However, the industrial structure adjustment needs to be strengthened and the effective use of the agroecological resources should be promoted. In particular, the current lag phase, which is due to the lag of the transformation and upgrading of economic restructuring leading to the irrational use of the agricultural eco-economic system and the loss of labor, is causing several problems. To reduce the large outputs produced outside the system, a new benign coupling mechanism should be constructed through the optimal combination of policies, information (technology and market), agricultural resources, agricultural industries and other factors. With improvements in these factors, coupling in the agricultural industry-resource system would be optimized (Wang et al., 2017). Furthermore, the agroeconomic system failed to produce positive feedback to the agroecosystem. To improve the feedback, Wang et al. (2017) proposed introducing a carbon sink industry in areas where cropland has been returned to forestland to strengthen economic carbon sequestration and oxygen release (Deng et al., 2017). By increasing the potential for a carbon sink, breakthrough and growth points would be provided for the optimization and upgrading of the original agricultural industry-resource system. These actions would further optimize the interaction between the agricultural system and other systems (Persson et al., 2013).

\section{Conclusions}

This study used a structural equation model to analyze the surveyed data of 494 households in Ansai. The model clarified the action paths and the intensity of the coupling between the GGP and the agricultural eco-economic system in the study area. Because of the partial contradiction between the model and survey results for the agricultural eco-economic system, the development of the coupling between the GGP and the agricultural eco-economic system was suppressed to a certain extent, and only partial coordination was detected between the agroecosystem and the agroeconomic system and between the agroecosystem and the coupling effect.

Improvements in the ecological environment could provide a material guarantee for coupling to develop within the agricultural eco-economic system. In this study, optimizations of the agroecosystem were apparent within the agricultural eco-economic system. However, because of the poor utilization of the agroecological resources, the lag in agricultural economic development led to the development of poor coupling within the current agricultural eco-economic system.

To fully develop the coupling between the GGP and the agricultural eco-economic system, ecological construction should be strengthened, agricultural resources should be rationally allocated, abundant forest and grass resources should be fully utilized, and the industrial structure 
should be diversified. For example, a carbon sequestration industry would optimize the resources produced by the original agricultural industry. Additionally, the external value of ecological function should be quantified, and the healthy development of the agricultural eco-economic system in the region should be promoted. With these suggestions, a benign coupling could be achieved within the agricultural eco-economic system, which can fully positively develop the coupling between the GGP and the agricultural eco-economic system.

\section{Acknowledgements}

This study was supported by the National Natural Science Foundation of China (41571515), and the National Key Research and Development Program of China (2016YFC0501707, 2016YFC0503702). We sincerely thank Prof. LIU Guobin for his guidance on this study.

\section{References}

Aderson J C, Gerbring D W. 1988. Structural equation modeling in practice: A review and recommended two-step approach. Pyschological Bulletin, 103(3): 411-423.

Asah S T. 2008. Empirical social-ecological system analysis: From theoretical framework to latent variable structural equation model. Environmental Management, 42: 1077-1090.

Bennett M T. 2008. China's sloping land conversion program: Institutional innovation or business as usual? Ecological Economics, 65(4): 699-711.

Bertalanffy L V. 1987. General System Theory-Foundation Development, Applications (Reversion edition). New York: George Beazitler, 189-239.

Bollen K A. 1989. Structural Equations with Latent Variables. New York: Wiley, 55-70.

Brahim N, Blavet D, Gallali T, et al. 2011. Application of structural equation modeling for assessing relationships between organic carbon and soil properties in semiarid Mediterranean region. International Journal of Environmental Science \& Technology, 8(2): 305-320.

Byrne B M. 1998. Structural Equation Modeling with LISREL, PRELIS, and SIMPLIS; Basic Concepts, Applications, and Programming. Mahwah: Lawrence Erlbaum Associates, 66-74.

Byrne B M. 2001. Structural equation modeling with AMOS, EQS, and LISREL: Comparative approaches to testing for the factorial validity of a measuring instrument. International Journal of Testing, 1(1): 55-86.

Deng L, Liu S, Kim D G, et al. 2017. Past and future carbon sequestration benefits of China's grain for green program. Global Environmental Change, 47: 13-20.

Duncan T E, Duncan S C, Strycker L A. 2006. An Introduction to Latent Variable Growth Curve Modeling: Concepts, Issues, and Applications. Mahwah: Lawrence Erlbaum Associates, 93-105.

Gough L, Grace J B. 1999. Effects of environmental change on plant species density: Comparing predictions with experiments. Ecology, 80(3): 882-890.

Grace J B, Anderson T M, Scheiner O S M. 2010. On the specification of structural equation models for ecological systems. Ecological Monographs, 80(1): 67-87.

Grosjean P, Kontoleon A. 2009. How sustainable are sustainable development programs? The case of the sloping land conversion program in China. World Development, 37(1): 268-285.

Hung N T, Asaeda T, Manatunge J. 2007. Modeling interactions of submersed plant biomass and environmental factors in a stream using structural equation modeling. Hydrobiologia, 583(1): 183-193.

Jia X Q, Fu B J, Feng X M, et al. 2014. The trade off and synergy between ecosystem services in the Grain-for-Green areas in Northern Shaanxi, China. Ecological Indicators, 43: 103-113.

Kalaitzandonakes N G, Monson M J. 1994. An analysis of potential conservation effort of crp participants in the state of missouri: a latent variable approach. Journal of Agricultural \& Applied Economics, 26(1): 200-208.

Li Q R, Wang J J, Guo M C. 2012. Coupling relationship of ecological agricultural system of commodities in Ansai county based on structural equation model. Transactions of the Chinese Society of Agricultural Engineering, 28(16): 240-247. (in Chinese)

Li Q R, Amjath-Babu T S, Zander P, 2016a. Role of capitals and capabilities in ensuring economic resilience of land conservation efforts: A case study of the grain for green project in China's Loess Hills. Ecological Indicators, 71: 636-644.

Li Q R, Liu Z, Zander P, et al. 2016b. Does farmland conversion improve or impair household livelihood in smallholder agriculture system? A case study of Grain for Green project impacts in China's Loess Plateau. World Development 
Perspectives, 2: 43-54.

Li Q R, Amjath-Babu T S, Sieber S, et al. 2018. Assessing divergent consequences of payments for ecosystem services (PES) on rural livelihoods: A case-study in China's Loess Hills. Land Degradation \& Development, 29(10): 3549-3570.

Li Y, Wang J J, Liu P L, et al. 2018. Study on the synergic relationship between grain for green and agricultural eco-economic social system-A case study in Ansai county. Journal of Natural Resources, 33(7): 1179-1190. (in Chinese)

Liu C, Wu B. 2010. Grain for Green Programme in China: Policy making and implementation? Policy Briefing Series, 60: 1-17. The University of Nottingham, China Policy Institute, Nottingham.

Liu J G, Li S X, Ouyang Z Y, et al. 2008. Ecological and socioeconomic effects of China's policies for ecosystem services. Proceedings of the National Academy of Sciences of the United States of America, 105(28): 9477-9482.

Liu J X, Li Z G, Zhang X P, et al. 2013. Responses of vegetation cover to the Grain for Green Program and their driving forces in the He-Long region of the middle reaches of the Yellow River. Journal of Arid Land, 5(4): 511-520.

Maruyama G M.1998. Basics of Structural Equation Modeling. Thousand Oaks: Sage.148-149.

McCune B, Grace L B. 2002. Analysis of Ecological Communities Gleneden Beach. Oregon: MjM Software Design, 1-300.

Persson M, Moberg J, Ostwald M, et al. 2013. The Chinese Grain for Green Programme: Assessing the carbon sequestered via land reform. Journal of Environmental Management, 126: 142-146.

Ren J Z, He D H, Wang N, et al. 1995. Models of coupling agro-grassland systems in desert-oasis region. Acta Prataculturae Sinica, 2: 11-19. (in Chinese)

Rong T S. 2009. AMOS and Research Methods. Chongqing: Chongqing University Press, 25-33. (in Chinese)

Smith J, Scherr S J. 2003. Capturing the value of forest carbon for local livelihoods. World Development, 31(12): $2143-2160$.

State Forestry Administration of the People's Republic of China. 2016. China forestry development report 2016, Beijing, China. [2016-12-09]. http://www. forestry.gov.cn/.main/62/content-957369.html. (in Chinese)

Steiger J H. 1990. Structural model evaluation and modification: An interval estimation approach. Multivariate Behavioral Research, 25(2): 173-189.

Sutton-Grier A E, Kenney M A, Richardson C J. 2010. Examining the relationship between ecosystem structure and function using structural equation modelling: A case study examining denitrification potential in restored wetland soils. Ecological Modeling, 221(5): 761-768.

Tomarken A J, Waller N G. 2005. Structural equation modeling: strengths, limitations, and misconceptions. Annual Review of Clinical Psychology, 1(1): 31-65.

Uchida E, Xu J, Rozelle S. 2005. Grain for green: cost-effectiveness and sustainability of China's conservation set-aside programme. Land Economics, 81(2): 247-264.

Uchida E, Rozelle S, Xu J. 2009. Conservation payments, liquidity constraints, and off-farm labor: Impact of the Grain-for-Green Program on rural households in China. American Journal of Agricultural Economics, 91(1): 70-86.

Wang J J, Guo M C, Jiang Z D, et al. 2010. The construction and application of an agricultural ecological-economic system coupled process model. Acta Ecological Sinica, 30(9): 2371-2378. (in Chinese)

Wang J J, Wang Z S, Cheng S M, et al. 2017. Eco-economic thinking for developing carbon sink industry in the de-farming regions. Chinese Journal of Applied Ecology, 28(12): 4109-4116. (in Chinese)

Wang X H, Shen J X, Zhang W. 2014. Emergy evaluation of agricultural sustainability of Northwest China before and after the grain-for-green policy. Energy Policy, 67: 508-516.

Werner C, Schermelleh-Eagel K. 2009. Structural equation modeling: Advantages, challenges, and problems. Introduction to Structural Equation Modeling with LISREL. Goethe University, Germany.

Wright S. 1934. The method of path coefficients. Annals of Mathematical Statistics, 5(3): 161-215.

Xu Z, Xu J, Deng X, et al. 2006. Grain for Green versus grain: conflict between food security and conservation set-aside in China. World Development, 34(1): 130-148.

Yao S, Guo Y, Huo X. 2010. An empirical analysis of the effects of China's land conversion program on farmers' income growth and labor transfer. Environmental Management, 45(3): 502-512. 